\title{
DIGRESSÕES SOBRE SAÚDE, ENVELHECIMENTO E VIDA SAUDÁVEL NA CONTEMPORANEIDADE
}

\author{
Monique Borba Cerqueira ${ }^{1}$
}

\begin{abstract}
RESUMO
Na busca por uma vida saudável se reprograma o corpo, o comportamento e os modos de vida do envelhecimento contemporâneo. 0 processo de envelhecer tem sido objeto de inúmeras práticas vinculadas ao discurso médico do "envelhecimento saudável", na tentativa de maximizar a saúde e as condições de vida dos mais velhos. Segundo o envelhecimento ativo, o envelhecer é equacionado a partir da entronização do rejuvenescimento, no qual os mais velhos devem recuperar espaços produtivos, praticar atividades físicas e autorregular a própria saúde em busca do equilíbrio orgânico e da aparência jovial. Este artigo discorre sobre as transformações operadas pelas novas tecnologias da saúde em nosso tempo e seus rebatimentos nos modos de envelhecer.
\end{abstract}

Palavras-Chave: Envelhecimento. Saúde. Biopoder. Biossociabilidade.

\section{DIGRESSIONS ON HEALTH, AGING AND HEALTHY LIFESTYLES TODAY}

\begin{abstract}
In the pursuit of a healthy life, we reprogram the body, the behavior and lifestyles of contemporary aging. The aging process has been the subject of numerous practices linked to the medical discourse of "healthy aging" in an attempt to maximize the health and living conditions of the elderly. According to active aging, aging is made equivalent

\footnotetext{
${ }^{1}$ Pesquisadora Científica do Núcleo de Práticas e Políticas de Saúde do Instituto de Saúde e PósDoutoranda do Programa de Pós-Graduação em Ciências Sociais da Pontifícia Universidade Católica de São Paulo - PUC/SP, Brasil. moniqueb@terra.com.br
} 
to the enthronement of rejuvenation, in which the elderly should regain productive spaces, do physical activities and self-regulate their health in search of organic balance and youthful appearance. This article discusses the transformations generated by new health technologies in our time and their repercussions in the ways of aging.

Keywords: Aging. Health. Biopower. Biosociality.

$\mathrm{N}$ os dias atuais o envelhecimento impõe grandes desafios ao Estado, ao mercado e às relações sociais. Trata-se de um tema que se distingue pelo impacto que vem causando ao conjunto da sociedade. Compreender a experiência existencial dos indivíduos, ao refletir sobre os percursos do envelhecer, torna-se uma necessidade imperiosa.

No mundo contemporâneo, corpo e saúde aparecem como temas fundamentais na reflexão sobre as relações sociais. Isto porque o corpo enquanto construção social possui uma longa tradição ligada ao disciplinamento e à ordenação das sociedades. Por outro lado, a saúde pode ser compreendida como um espaço de representações simbólicas e lutas políticas cuja força inigualável de reprodução normativa estabelece novos valores definidores do que seria uma vida boa e desejável. Devido a inúmeras transformações recentes, a saúde tornou-se um importante objeto de desejo e território de conforto da civilização.

Corpo, saúde e velhice são categorias que necessariamente se cruzam e se interpelam no plano social, ao tornar visíveis suas interfaces e constantes rearranjos socioculturais. A velhice tem sido objeto de inúmeras práticas vinculadas ao discurso médico do "envelhecimento saudável", da "qualidade de vida", da "melhor idade", na tentativa de maximizar a saúde e as condições de vida dos mais velhos.

Nesse contexto se inscrevem campos de problematização da vida em sociedade, do envelhecimento e do corpo que sinalizam para a existência de novas lógicas, nas que a saúde é alcançada, aumentando-se as capacidades morais e autodisciplinares do indivíduo. Esse quadro aponta para alterações na cena social que não se limitam aos avanços tecnológicos da biomedicina, mas dizem respeito a questões éticas, políticas e culturais que indicam o surgimento de uma fusão entre saúde e identidade (RABINOW; ROSE, 2006).

É a partir das figurações contemporâneas do biopoder, num cenário no qual proliferam discursos de verdade sobre o caráter vital dos seres humanos, bem como modos de subjetivação que revelam práticas de si realizadas em nome da saúde pessoal ou coletiva, é que surge a formação de novos sujeitos sociais - biocidadania, cidadania somática, biossociabilidades. 
Na atualidade, os parâmetros que alicerçam a existência individual em relação à saúde repousam sobre o contexto da biologização do sentido da vida e do discurso sobre 0 risco, que não apenas estabelecem comportamentos, mas regulamentam escolhas, transformando o medo e a culpa em atributos necessários ao cumprimento das regras para uma vida saudável. São exigidas formas cada vez mais refinadas de purificação dos indivíduos obedientes às normas que garantem saúde e longevidade. Nessa direção, 0 autogerenciamento da vida passa necessariamente pela aspiração social de práticas que promovem o monitoramento da saúde como signo de "bem viver". Portanto, torna-se necessário planejar e cumprir metas baseadas no conhecimento médico e biotecnológico através da busca de cuidados corporais, médicos, higiênicos, alimentares e estéticos (PREMEBIDA; ALMEIDA, 2010).

No caso do envelhecimento saudável enquanto discurso permanentemente veiculado pela mídia, soma-se o fato de que a questão do envelhecimento é equacionada a partir da entronização do rejuvenescimento, em que os mais velhos devem recuperar espaços produtivos, praticar atividades físicas, fazer monitoramento médico e, eventualmente, submeter-se aos tratamentos cosméticos e cirúrgicos capazes de restituir a aparência jovial. Longevidade e vitalidade são palavras de ordem para a reinserção social do idoso numa sociedade reduzida a um tipo de individualismo em que o sujeito é agente e produtor de autonomia como auto peritagem - capacidade de se especializar no controle de si mesmo, administrando as próprias taxas de colesterol, peso, ingestão de álcool e tudo que possa macular a saúde. São as chamadas práticas de bioascese que vêm submetendo todos os grupos de idade, segundo os ideais de uma vida saudável.

Este artigo pretende discutir como as transformações ocorridas nas políticas da vida, a partir das reconfigurações operadas pelas novas tecnologias da saúde, encontram rebatimento nos modos de envelhecer.

\section{A MAXIMIZAÇÃO DA SAÚDE E O DISCURSO PARA UMA VIDA SAUDÁVEL}

A emergência dos debates contemporâneos no plano teórico e conceitual evidencia modificações de fundo na organização da vida humana, segundo uma lógica que atravessa desde as estruturas políticas, representações simbólicas e processos sociais que regulam as instituições e orientam a vida em sociedade. A intervenção prática das tecnociências no corpo e no planeta nas últimas décadas revelou nítidas redefinições no horizonte da saúde.

Sugerindo um marco exemplar, a vida passa a ser repensada a partir da alteração do conceito de morte que ocorre "através da suspensão da morte celular" para conservação dos órgãos para transplante (NUNES, 2006, p. 6). 0 que chama atenção 
nesse processo é que ao longo das transformações — envolvendo saúde, doença, vida e intervenção médica - profundas alterações sociais têm se evidenciado. A saúde conquistou um relevo social sem precedentes:

Com efeito, aquilo que é do bios - a vida, o corpo e a saúde - emerge como tema que vem assumindo enorme relevância junto com um corpo de saber e da investigação em clara ascensão e alargamento, e que cruza uma diversidade de contribuições (inter) disciplinares, teóricas, metodológicas, e temáticas que tem vindo a convergir nos estudos sociais sobre saúde (FILIPE, 2010, p. 76).

Foucault (2003) chamava a atenção para o fenômeno da administração dos corpos, ao descrever o biopoder enquanto poder exercido sobre a vida individual ou coletiva, cuja intervenção ocorria por meio das biopolíticas e tecnologias disciplinares (FOUCAULT, 2003).

$\mathrm{Na}$ atualidade, novos matizes associados ao biopoder têm se notabilizado numa "reconfiguração da verdade sobre nós próprios", na que "a própria definição de humano é um output das ciências da vida e da biomedicina.” (CASELAS, 2009, p. 87).

De forma contundente, as alterações ocorridas no estatuto do conhecimento técnico-científico contemporâneo têm provocado importantes modificações nas concepções de saúde, doença e corpo, impondo novos padrões à vida social que ultrapassam as fronteiras do festejado progresso tecnológico. As chamadas tecnologias de manipulação da vida, especialmente aquelas circunscritas ao nível molecular, têm remetido à "possibilidade de perfectibilidade indefinida do corpo humano." (FERREIRA; PEDR0, 2009, p. 177). É nesta direção que a produção e reprodução da vida apontam para a utopia da imortalidade. Sfez (1995) cita em uma passagem de seu livro a história hipotética de um homem que em 2050 é ainda um jovem de noventa anos, quando recebe a notícia do seu médico de que vai morrer. Ao questionar a equipe sobre as alternativas da ciência para o seu caso, o médico responde claramente que seu corpo vai mesmo morrer, mas naquele momento, ele se tornava candidato a um transplante de alma. 0 procedimento ocorreria dias depois de forma bem sucedida. Essa anedota ilustra 0 argumento do autor sobre o processo de purificação do homem na Utopia da Saúde Perfeita, por ocasião do progresso das tecnociências e seus audaciosos projetos: Genoma Humano, Biosfera II e Vida Artificial.

Não há dúvida sobre os benefícios que as novas tecnologias disponibilizam para a biomedicina e o campo das práticas médicas, mas é emblemático o poder de ampliação progressiva que a lógica de perfectibilidade das tecnociências vem impondo à dinâmica social, reconfigurando a cultura e os valores contemporâneos, dentre eles o conceito de saúde. 
Com efeito, os conceitos de saúde e estilo de vida encontram-se cada vez mais ancorados na ideia de um corpo saudável e com potencialidades de majoração por via técnica, o que é elucidativo da crescente entronização do valor saúde nas sociedades modernas, como também é um indicador expressivo do impacto das novas tecnologias médicas na produção de novos significados sobre o corpo, a saúde e a própria vida humana (RAPOSO, 2009, p. 1).

E se o estilo de vida produz adoecimento ou morte, o indivíduo deve aderir ao compromisso com a autovigilância, o que gera culpabilização dos pacientes e despolitização do problema (FERREIRA NETO et al., 2009).

É a partir dos modos de subjetivação que os indivíduos serão levados a atuar sobre si em nome da própria vida ou da saúde (RABINOW; ROSE, 2006). De uma forma jamais vista na história da humanidade, com a configuração atual das tecnociências, a otimização do corpo saudável passa a ser objeto de gerenciamentos capazes de remodelar e alterar a capacidade vital do ser humano (ROSE, 2007).

A vida como fundamento da existência, toda sua singularidade e multiplicidade, fica reduzida a chavões como "viver bem", "viver com qualidade", "viver com saúde". A vida transforma-se de forma empobrecida, igualando-se a um estilo de vida (COELHO; FONSECA, 2007; RAPOS0; AEROSA, 2009).

Tais deslocamentos fazem com que a dor e o sofrimento precisem ser banidos. "Sofrer transforma-se em avesso do viver" (COELHO; FONSECA, 2007, p. 65). Mas a dor de quem não participa dos ideais de saúde perfeita e não persegue uma vida saudável e feliz se intensifica, assim como o medo, a vergonha, a culpa de não conseguir administrar a saúde do próprio corpo. Como observa Foucault (2003, p. 158), "A ideologia da saúde e do corpo perfeito nos leva a contemplar as doenças que retorcem a figura humana como sinônimo de fracasso pessoal."

As tecnologias da saúde, ao remeterem à promessa de "mais saúde", são a porta de entrada para a expansão e aceitação social das inovações tecnológicas no campo das ciências da vida e da biomedicina. Como parte desse movimento, o sujeito passa a inscrever sua biografia a partir de parâmetros biológicos, neurológicos e bioquímicos.

Nesse contexto, corpo, saúde e beleza se fundem. 0 corpo é construído, consumido, padronizado no sentido de sua purificação e apuração estética, sendo delineado pela alimentação natural, orientado para a reposição de hormônios, a prevenção de DSTs, a redução de sal, dos danos por drogas. 0 sujeito se "substantiva na aparência do corpo" (PREMEBIDA; ALMEIDA, 2010, p. 19). Assim, os "fracos", aqueles que não se adequam ao padrão do autocontrole são os únicos responsáveis pelo incômodo que provocam com seus corpos indesejados e desestabilizados. É o que pode 
ser chamado de "fascismo da saúde", a vigilância e o controle exercido pelos corpos saudáveis sobre os corpos impuros (EDGLEY; BRISSET, 1990, p. 260).

A partir do discurso da saúde perfeita se inscreve o problema da emergência de identidades, grupos e práticas coletivas que Rabinow (1999) nomeia como biossociabilidade, reconhecendo o quanto o fenômeno da biomedicina tem moldado a subjetividade. 0 sujeito da biossociabilidade é objeto da desregulamentação cuja liberdade, muitas vezes, pode se reduzir a opção dos riscos que se pretende correr (SZAPIR0, 2005).

Os modos de existência marcados pela construção de uma bioascese e biossociabilidade, segundo práticas saudáveis, investem no corpo e na saúde como atributos fundamentais.

$\mathrm{Na}$ biossociabilidade criam-se novos critérios de mérito e reconhecimento, novos valores com base em regras higiênicas, regimes de ocupação de tempo, criação de modelos ideais de sujeito baseados no desempenho físico. As ações individuais passam a ser dirigidas com o objetivo de obter melhor forma física, mais longevidade, prolongamento da juventude, etc. Todo um vocabulário médico-fisicalista baseado em constantes biológicas, taxas de colesterol, tono muscular, desempenho físico, capacidade aeróbica populariza-se e adquire uma conotação quase moral, fornecendo os critérios de avaliação individual. Ao mesmo tempo todas as atividades sociais, lúdicas, religiosas, esportivas, sexuais são ressignificadas como práticas de saúde (ORTEGA, 2008, p. 31).

Novas sociabilidades sob a regulação do biológico definem um modo de cultuar e disciplinar o corpo, reverenciando a saúde: "toma-se a vida como projeto medido pelo rigor, pelo cuidado com o excesso, com tudo que é da ordem das paixões." (SZAPIR0, 2005, p. 35). 0 prazer destituído de exagero e desregramento é descolado de sua intensidade, dando lugar à aspiração equilibrada por uma vida saudável.

\section{ENVELHECIMENTO E SAÚDE}

A abordagem do envelhecimento ativo é baseada no reconhecimento dos Direitos Humanos das pessoas mais velhas e nos princípios de independência, participação, dignidade, assistência e auto realização estabelecidos pela Organização das Nações Unidas. 0 envelhecimento ativo, concepção introduzida pela Organização Mundial da Saúde (OMS), é um desdobramento do envelhecimento saudável e pretende contribuir para que os idosos permaneçam cada vez mais tempo no mercado de trabalho, mantendo-se saudáveis, ativos e autônomos o maior tempo possível. 
A Organização Mundial de Saúde acrescenta que se desejarmos o envelhecimento como uma experiência positiva, o que implica uma vida mais longa, esta deve ser acompanhada de oportunidades contínuas de saúde, participação e segurança (WORLD HEALTH ORGANIZATION, 2005). Ainda, segundo o documento, "Os próprios idosos e a mídia devem liderar uma imagem nova e mais propositiva da terceira idade." (WORLD HEALTH ORGANIZATION, 2005, p. 44).

Santos (1997) lembra como os Direitos Humanos se transformaram na "linguagem da política progressista" que em nome dos objetivos de desenvolvimento clamavam por emancipação: "[...] enquanto forem concebidos como direitos universais, os direitos humanos tenderão a operar como localismo globalizado - uma forma de globalização de cima-para-baixo." (SANTOS, 1997, p. 111).

De fato, o traço universalista presente no discurso e na política oficial das Nações Unidas tem norteado as políticas e o significado do envelhecimento, o que se traduz em uniformizar ações, escolhas, comportamentos e visões de mundo. Tal é a missão da Organização Mundial de Saúde integrada ao Ministério da Saúde brasileiro: informar visando discutir e formular planos de ação que promovam um envelhecimento saudável e ativo (WORLD HEALTH ORGANIZATION, 2005).

Multiplicam-se as autoridades e saberes considerados competentes para enunciar a verdade sobre o envelhecimento. Sob essa lógica, um discurso alarmista sobre 0 aumento da população idosa no mundo soa como aviso ou sinal de cautela, conclamando ao esforço solidário e à reparação social.

Brasília - A Organização Mundial da Saúde (OMS) alerta os países para adoção de medidas que garantam o envelhecimento saudável da população. [...] 0 alerta da OMS decorre da previsão de que, dentro de poucos anos, pela primeira vez, a população com mais de 60 anos de idade será maior que a de crianças com menos de 5 anos. Até 2050, 80\% dos idosos estarão vivendo em países pobres ou em desenvolvimento. De acordo com as recomendações da OMS, as autoridades de saúde precisam conter as doenças crônicas não transmissíveis que mais atacam os idosos, como ataque cardíaco, câncer, diabetes e doenças pulmonares. De acordo com a diretora-geral da OMS, Margareth Chan, as pessoas em países pobres têm risco, quatro vezes maior, de morrer ou sofrer alguma deficiência por causa de uma doença crônica em comparação as que vivem em nações ricas. Chan observa que a maioria das enfermidades relacionadas à velhice pode ser prevenida ou submetida a tratamento de baixo custo. Exemplo disso é o controle da pressão sanguínea, fator de diminuição do risco de infarto. No entanto, menos de $15 \%$ dos idosos em países pobres e em desenvolvimento adotam procedimentos para controlar a pressão alta. A organização recomenda a adoção de medidas para diagnóstico precoce de doenças crônicas e a promoção de hábitos saudáveis em todas as faixas etárias (PIMENTEL, 2012). 
A "ameaça" quanto ao acelerado envelhecimento populacional é um importante marcador de prudência e vigilância presente na produção acadêmica sobre velhice e saúde. 0 persecutório e apavorante temor do que acontecerá diante do fenômeno do envelhecimento demográfico passa a ser uma preocupação central no âmbito da ciência, da política e da economia. Este é o principal argumento capaz de justificar a redefinição de políticas e programas que visam transformar o perfil do envelhecimento no planeta. Trata-se da política "supostamente despolitizada" dos Direitos Humanos, das declarações e compromissos assumidos por organizações internacionais que, por fim, acaba servindo a fins políticos e econômicos específicos (ZIZEK, 2010, p. 25).

Não obstante, observa-se no país a existência de mudanças inequívocas na paisagem do envelhecer nas últimas décadas. Os idosos vêm sendo retirados de um nicho historicamente marginal e oculto, na tentativa de que se tornem sujeitos de realização pessoal, ganhando visibilidade política e ocupando uma nova topografia social.

Nesse contexto, é segundo a ótica da saúde, definida sob uma perspectiva ampla, que se pretende enfrentar os desafios para a obtenção de modos de vida mais saudáveis na velhice. A ênfase na assistência médica é substituída pela valorização da atenção básica e pelo estímulo à prática de estilos de vida saudáveis, no sentido de envolver a todos nos cuidados de saúde. Este é um importante deslocamento realizado pela Promoção da Saúde, estratégia fundamental à política do envelhecimento ativo, na qual os idosos passam a ser gestores da própria saúde.

0 Programa do Ministério da Saúde "Brasil Saudável" envolve uma ação nacional para criar políticas públicas que promovam modos de viver mais saudáveis em todas as etapas da vida, favorecendo a prática de atividades físicas no cotidiano e no lazer, o acesso a alimentos saudáveis e a redução do consumo do tabaco. Essas questões são a base para 0 envelhecimento saudável, um envelhecimento que signifique também um ganho substancial de qualidade de vida e saúde (WORLD HEALTH ORGANIZATION, 2005, p. 3).

Multiplicam-se as estratégias de intervenção coletiva em nome da vida e da saúde. A lógica da Promoção da Saúde, as políticas de prevenção e o envelhecimento ativo se articulam para tornar possível a instrução dos segmentos mais idosos, desenvolvendo sua capacidade de agir em benefício da própria saúde.

Aprovada em 30 de março de 2006, a Política Nacional de Promoção da Saúde (PNPS) dá diretrizes e aponta estratégias de organização das ações de promoção da saúde para garantir a integralidade do cuidado no Sistema Único de Saúde (BRASIL, 2006). No entanto, é no campo de conhecimento da saúde coletiva que ocorrem os debates mais contundentes sobre a revalorização do discurso da promoção da saúde. Do 
ponto de vista mais geral, identifica-se de forma recorrente na literatura a dificuldade de se definir conceitualmente e de se operacionalizar as ações de promoção da saúde, segundo um enfoque mais reflexivo ou crítico (CARVALHO, 2004; CAMARGO JUNIOR, 2007; CZERESNIA, 2003; IGLESIAS; DALBELLO-ARAUJO, 2011; TRAVERSO-YÉPEZ, 2007). Obscura, inconsistente e contraditória, a promoção da saúde padece da mesma dificuldade de definição do conceito de saúde (TRAVERSO-YÉPEZ, 2007, p. 225). Ainda assim, a promoção da saúde é uma abordagem cara a setores progressistas da saúde coletiva que acreditam no seu deslocamento da esfera moral e prescritiva para uma visão centrada no protagonismo dos sujeitos (CARVALHO, 2004; IGLESIAS; DALBELLOARAUJO, 2011; MARTINS, 2004). Esta é, inclusive, uma discussão que requer centralidade nas áreas técnicas e de produção do saber voltadas para os estudos do envelhecimento.

Um interessante trabalho de investigação sobre o texto da Política Nacional de Promoção de Saúde acusa vários impasses e aspectos problemáticos que aparecem no documento. Vale a pena destacar a identificação de um "discurso político-prescritivo" que "tende a se mostrar como algo acabado, inquestionável e, especialmente, fácil de acontecer" (TRAVERSO-YÉPEZ, 2007, p. 232). Mas a promoção da saúde "num estalar de dedos" só ocorre no texto limpo e objetivo do Ministério da Saúde. 0 que é importante assinalar no documento é a sua distância entre a população-alvo e as práticas de saúde, o que se evidencia na impossibilidade de diálogo dada por especialistas, gestores e técnicos, sempre legitimados em sua condição de autoridades em saúde (TRAVERSOYÉPEZ, 2007, p. 234). 0 modo como o texto constrói de forma ambígua seus principais atores sociais aponta para uma visão da coletividade como uma totalidade homogênea, "negligenciando as profundas diferenças socioculturais" dos chamados "cidadãos", recorrentemente citados por um discurso verticalizado (TRAVERSO-YÉPEZ, 2007, p. 233). Sob essa ótica, o sujeito deve acatar determinações, adotar posturas e comportamentos que os técnicos consideram saudáveis, corroborando uma política de promoção da saúde cujo discurso político é inequivocamente prescritivo.

[...] parte importante dos projetos de promoção à saúde tem dificuldade para superar o enfoque behaviorista e mantém o foco de sua atenção para ações voltadas para a regulação da vida social e para criação de critérios que delimitem o sentido de viver saudável. A autonomia possível é, quase sempre, uma autonomia regulada, uma vez que os indivíduos tendem a seguir regras e normas concebidas por expertos e pelos parâmetros construídos pelas Políticas Públicas Saudáveis (CARVALHO, 2004, p. 674).

A promoção da saúde nesse contexto nada mais é que uma biopolítica exercida sobre o corpo na busca pelo controle da vida. São muitas as ações voltadas para 0 adiamento da morbidade e incapacidade física na velhice. Predomina a visão biológica 
do envelhecer, obcecada com o corpo, mas com pouco interesse em outras dimensões da vida. As práticas de saúde, a seguir o modelo da pedagogia médica, reforçam o discurso moralizante da prudência que, repetidamente, visa garantir cada vez mais obediência e escolhas acertadas que minimizem os riscos em populações que envelhecem. 0 envelhecimento é concebido em conformidade com padrões rigorosos de normatização.

\section{OS DESAFIOS DE CUIDAR DA PRÓPRIA SAÚDE}

No momento em que as técnicas de visibilidade do corpo demonstram, além do lugar, da natureza e do grau de desenvolvimento da afecção, os riscos que o indivíduo tem de manifestar certa doença, os critérios de definiç̧ão do são e do enfermo se modificam. Pois há doença no silêncio dos órgãos. E a saúde não pode mais ser definida pela ausência de doença atual (BRUNO, 2006, p. 67).

Controlar, prever, prevenir riscos, tal é o papel do discurso do risco (CASTEL, 1987). Novas identidades são assumidas em função da gestão dos riscos no contexto da modernidade tardia (GIDDENS, 1991). A máxima do bem-estar e o fenômeno das biossociabilidades não poderiam existir dissociados da ideia de risco. A autoconsciência do "ser saudável" se tornou um parâmetro existencial, enquanto o auto melhoramento é exercido como estratégia de reorganização do mundo social que faz do indivíduo 0 zelador de si mesmo.

Sob esta perspectiva, o contexto sociocultural do envelhecimento é amplamente afetado pela complexidade dos processos sociais que informam a construção de identidades e sociabilidades. É pela via da corporeidade e seus referentes saúde e doença que novos padrões sociais são definidos no processo de envelhecimento, tendo como base procedimentos cientificamente comprovados e moralmente recomendados.

$\mathrm{Na}$ formatação desta nova moralidade baseada no autocontrole biológico, a gestão do corpo deve extirpar, sobretudo, sal, açúcar, gorduras e os demais "maus" hábitos, uma vez que "o envelhecimento saudável decorre da menor prevalência de doenças crônicas e/ou das suas consequências funcionais." (JACOB-FILHO, 2009, p. 31).

0 desenvolvimento de hábitos e comportamentos saudáveis reforçados pela ideia de autonomia constitui a Promoção da Saúde do Idoso enquanto estratégia capaz de dirigir suas ações para reduzir, nesta população, o risco de adoecer e de morrer (ORGANIZACION PANAMERICANA DE LA SALUD, 1992). Nessa lógica, a redução dos custos da assistência em saúde aparece como o pano de fundo sobre o qual os indivíduos são conduzidos a um comportamento de auto responsabilização por sua saúde. 
Trata-se de promover e procurar incutir práticas de autocuidado na rotina dos indivíduos. A informação sobre saúde é prioridade máxima, pois todos devem obter com facilidade subsídios para cuidar de si. Uma pesquisa antropológica realizada com um grupo de idosas hipertensas no morro da Mangueira relata a visão de algumas pacientes.

Nas falas das idosas, chama atenção a resignação com sua doença e a reprodução do discurso médico pedagógico que prega a atenção constante com a saúde: Posso me esquecer de comer, mas não posso me esquecer do remédio, afirmou uma das mulheres. A figura do médico ganha contornos persecutórios: na consulta mensal, os participantes manifestavam a preocupação em relatar se estavam cumprindo ou não a dieta prescrita (LEIBING; GROISMAN, 2004, p. 288).

A prevenção surge como a melhor forma de manter ou prolongar a saúde, já que ainda não foram desvendados os mecanismos que levam à deterioração das células e moléculas do corpo humano que resultam no envelhecimento. Para resistir aos transtornos provocados pela velhice é preciso se engajar no movimento do "bom envelhecer".

[...] Imaginamos que resistir à entropia da velhice signifique montar estratégias que permitam reduzir o ritmo da desorganização, que signifique adotar um regime ou um estilo de vida que reduza os efeitos visíveis e sensíveis do processo de desestruturação, mantendo a vitalidade e a autonomia. No plano do corpo, mantendo padrões circulatórios, digestivos, de flexibilidade, resistência e força, que crie a imagem de um funcionamento fisiológico mais novo que o cronológico. No plano social, criando novos pertencimentos e relacionamentos que mantenham em bom funcionamento a sociabilidade, o prestígio, o reconhecimento e a circulação social (SANTIAGO; LOVISOLO, 1997, p. 95).

0 discurso da qualidade de vida e da vida saudável que atualmente legitimam 0 corpo nos diferentes grupos de idade, exige graus de performance de cada indivíduo, a partir de escolhas e comportamentos adequados e corretos. No caso da velhice, a exigência parece mais complexa, uma vez que as condutas saudáveis têm implícita uma "volta a passado", segundo a qual se deve atingir patamares de rejuvenescimento que favoreçam a aceitação e reinserção social, mantendo-se compromissos duradouros com o próprio corpo. É através de um ideal (jovem) de envelhecimento que o sujeito volta a ser ágil e produtivo que se abrem novos espaços sociais.

A modelagem de um comportamento "biologicamente correto" articulada a uma estética da juventude, que funciona como senha para inclusão e circulação social na 
esfera pública, evidencia os limites enfrentados pela população idosa ao protagonizar a recente transformação nos padrões de envelhecimento.

Enquanto uma política de reciclagem biológica dos corpos chega à velhice amparada pelo discurso da prevenção e do controle dos riscos, acredita-se resgatar os idosos da rota patológica em direção à morte para conduzi-los aos avanços da biomedicina.

Biologicamente esquadrinhados, monitorados e formatados para sobreviver ao futuro, os idosos vivem novos tempos nos quais a maior aspiração de suas vidas pode se limitar a obter saúde e a viver cada vez mais. Mas, a saúde enquanto promessa de felicidade se esvazia, ao sonegar o universo de escolhas e a pluralidade dos regimes de sensação, liberdade e experimentação dos sujeitos que envelhecem.

Há que se considerar que com a emergência das biossociabilidades um vasto campo de pesquisa, ainda pouco explorado, anuncia-se. No tocante à problemática do envelhecimento, trata-se de questionar o estatuto de verdade presente na complexa equação "vida saudável", discutir suas afirmações, seu status de crença e influência sobre os modos de vida daqueles que envelhecem. Nesse sentido, conhecer a visão dos atores é indispensável no sentido de descartar maniqueísmos, considerando desde as conquistas até as formas de obediência e transgressão frente às normas e práticas associadas a uma vida saudável.

\section{CONSIDERAÇÕES FINAIS}

Pensar os desafios implícitos nos processos de envelhecer significa não perder de vista os múltiplos cenários, perspectivas e forças em disputa.

Assistimos nas últimas décadas a uma inflexão que aponta para a emergência de uma nova sensibilidade quanto à importância e ao trato atribuído aos problemas da velhice no país, evidenciando uma recodificação do saber e dos processos de envelhecimento. Inegavelmente, há uma série de avanços e pontos positivos. A introdução das práticas de autocuidado e projetos de interação social, quando promotores de autonomia, têm ressignificado o universo pessoal de idosos, assim como a multiplicação de bens e serviços dirigidos aos mais velhos são algumas das valiosas transformações já ocorridas.

Não obstante, observa-se que com os avanços da biomedicina se reprograma 0 corpo e o comportamento contemporâneo. As alterações físicas e mentais presentes nos processos de envelhecer são objeto quase exclusivo do saber médico e das estratégias do "não envelhecimento", seus complexos vitamínicos, suplementos alimentares e itens infindáveis na esfera do consumo. A saúde é glamourizada, maximizada e diluída no solo cultural transformando-se em valor exponencial do nosso tempo. A vida social se 
rende à nova moral da saúde, reafirmando suas convicções inabaláveis e pré-condições de felicidade.

Nesse contexto, as biossociabilidades e suas formas remetem a novos olhares sobre o fenômeno e os processos de envelhecer, nos quais a saúde deve ser questionada quanto ao seu papel primordial na afirmação da vida humana.

\section{REFERÊNCIAS}

BRASIL. Ministério da Saúde. Política Nacional de Promoção da Saúde. Brasília, 2006. BRUNO, Fernanda. 0 biopoder nos meios de comunicação: 0 anúncio dos corpos virtuais. Revista da Escola Superior de Propaganda e Marketing: Comunicação, mídia e consumo, São Paulo, v. 3, n. 6, p. 63-79, 2006.

CAMARG0 JUNIOR, Kenneth Rochel. As armadilhas da "Concepção Positiva de Saúde". PHYSIS: Revista de Saúde Coletiva, Rio de Janeiro, v. 76, n. 1, p. 63-76, 2007.

CARVALHO, Sérgio R. As contradições da promoção da saúde em relação à produção de sujeitos e a mudança social. Ciência \& Saúde Coletiva, Rio de Janeiro, v. 9, n. 3, p. 669678, 2004.

CASTEL, Robert. A gestão dos riscos. Rio de Janeiro: Livraria Francisco Alves, 1987.

CASELAS, José. Figuras contemporâneas do biopoder. Saberes, Natal, v. 1, n. 2, p. 81-92, maio 2009.

COELHO, Debora Moraes; FONSECA, Tania Mara Galli. As mil saúdes: para aquém e além da saúde vigente. Psicologia \& Sociedade, Porto Alegre, v. 19, n. 2, p. 65-69, 2007.

CZERESNIA, Dina; FREITAS, Carlos M. (Org.). Promoção da saúde: conceitos, reflexões, tendências. Rio de Janeiro: Fiocruz, 2003. p. 39-53.

EDGLEY, Charles; BRISSETT, Dennis. Health Nazis and the cult of the perfect body: some polemical observations. Symbolic Interaction, v. 13, n. 2, p. 257-279, 1990.

FERREIRA, Jonatas; PEDR0, Rosa Maria Leite Ribeiro. Biossociabilidade e biopolítica: reconfigurações e controvérsias em torno dos híbridos nanotecnológicos. Redes, Buenos Aires, v. 15, n. 29, p. 177-196, 2009.

FERREIRA NETO, João; KIND, Luciana; BARROS, Jairo Stacanelli; AZEVEDO, Natália Silva; ABRANTES, Tatiana Marques. Apontamentos sobre a promoção da Saúde e Biopoder. Saúde e Sociedade, São Paulo, v. 18, n. 3, p. 456-466, 2009.

FILIPE, Ângela Marques. Entre bios e polis? Debates contemporâneos sobre saúde, biomedicina e biocidadania. Prisma Jurídico, São Paulo, v. 9, n. 1, p. 75-89, jan./jun. 2010. 
FOUCAULT, Michel. História da sexualidade: a vontade de saber. Rio de Janeiro: Graal, 2003. v. 1.

GIDDENS, Antony. As consequências da modernidade. São Paulo, Ed. Universidade Paulista, 1991.

IGLESIAS, Alexandra; DALBELLO-ARAUJ0, Maristela. As concepções de promoção da saúde e suas implicações. Cadernos de Saúde Pública, Rio de Janeiro, v. 19, n. 3, p. 291-298, 2011.

LEIBING, Annette; GROISMAN, Daniel. Tão alto quanto o morro: identidades localizadas de mulheres hipertensas na favela da Mangueira. In: LEIBING, Annette (Org.).

Tecnologias do corpo: uma antropologia das medicinas no Brasil. Rio de Janeiro: NAU, 2004.

MARTINS, André. Biopolítica: o poder médico e a autonomia do paciente em uma nova concepção de saúde. Interface: Comunicação, Saúde, Educação, Botucatu, v. 8, n. 14, p. 21-32, fev. 2004.

NUNES, João Arriscado. A pesquisa em saúde nas ciências sociais e bumanas: tendências contemporâneas. 2006. Disponível em:

<http://www.ces.uc.pt/publicacoes/oficina/ficheiros/253.pdf>. Acesso em: 20 maio 2012. JACOB-FILHO, Wilson. Fatores determinantes do envelhecimento saudável. Boletim do Instituto de Saúde, São Paulo, n. 47, abr. 2009.

PIMENTEL, Carolina. OMS celebra Dia Mundial da Saúde com campanha em favor do envelhecimento saudável. 2012. Disponível em:

$<$ http://agenciabrasil.ebc.com.br/noticia/2012-04-03/oms-celebra-dia-mundial-dasaude-com-campanha-em-favor-do-envelhecimento-saudavel>. Acesso em: 29 jun. 2012.

ORGANIZACION PANAMERICANA DE LA SALUD. La salud de los ancianos: una preocupación de todos/ Health of the elderly: a concern for all. Washington, 1992.

ORTEGA, Francisco. O corpo incerto: corporeidade, tecnologias médicas e cultura contemporânea. Rio de Janeiro: Garamond, 2008.

PREMEBIDA, Adriano; ALMEIDA, Jalcione. Biotecnologias, biopolítica e novas sociabilidades. UNOPAR Científica: Ciências Humanas e Educação, Londrina, v. 11, n. 2, 2010.

RABINOW, Paul. Antropologia da razão. Rio de Janeiro: Relume Dumará, 1999.

RABINOW, Paul; ROSE, Nikolas. Biopower today. Biosocieties, Cambridge, v. 1, n. 2, p. 195-217, 2006. 
RAPOSO, Helder; AEROSA, João. As novas tecnologias médicas e a reconfiguração da saúde: entre riscos e incertezas. In: CONGRESSO LUSO-AFRO-BRASILEIRO DE CIÊNCIAS SOCIAIS, 10., 2009. Anais... Braga, 2009.

ROSE, Nikolas. The politics of life itself: biomedicine, power and subjectivity in the Twenty-First Century. Oxford: Princeton University Press, 2007.

SANTIAGO, Leonéia Vitoria; LOVISOLO, Hugo. Master de natação-competição, aprimoramento e expressão. Motus Corporis, Rio de Janeiro, v. 4, n. 2, p. 84-101, 1997.

SANTOS, Boaventura S. Por uma concepção multicultural dos direitos humanos. Revista Crítica de Ciências Sociais, Coimbra, n. 48, p. 11-32, jun. 1997.

SFEZ, Lucien. A saúde perfeita: críticas de uma utopia. Lisboa: Instituto Piaget, 1995. SZAPIR0, Ana Maria. Em tempos de pós-modernidade: vivendo a vida saudável e sem paixões. Revista de Estudos e Pesquisas em Psicologia, Rio de Janeiro, ano 5, n. 1, p. 25-37, 2005.

TRAVERSO-YÉPEZ, Martha A. Dilemas na promoção da saúde no Brasil: reflexões em torno da política nacional. Interface: Comunicação, Saúde, Educação, Botucatu, v. 11, n. 22, p. 223-238, maio/ago. 2007.

WORLD HEALTH ORGANIZATION. Envelhecimento Ativo: uma política de saúde. Brasília, OPAS, Ministério da Saúde, 2005.

ZIZEK, Slavoj. Contra os direitos humanos. Revista Mediações, Londrina, v. 15, n. 1, p. 11-29, 2010. 